\title{
Indications for fine-needle aspiration in spongiform thyroid nodules
}

Pedro Weslley Rosario ${ }^{1,2}$

Dear Editor,

C or spongiform thyroid nodule that is not autonomous (suspected by low TSH - and confirmed by ${ }^{131}$ I or ${ }^{123}$ I scintigraphy), unless the patient has a high risk of malignancy, (i) the Brazilian Society of Endocrinology and Metabolism recommends fine-needle aspiration (FNA) if the nodule is $\geq 2 \mathrm{~cm}$ (1); (ii) the British Thyroid Association not recommends FNA (2); and (iii) the American Thyroid Association recommends FNA if the nodule is $\geq 2 \mathrm{~cm}$, but ultrasonographic follow-up without biopsy is considered to be an acceptable alternative (3).

We report the results of 165 patients who had at least one nodule $>5 \mathrm{~mm}$ that showed spongiform appearance on ultrasonography [defined as an aggregation of multiple microcystic components with thin echogenic walls in more than $50 \%$ of the nodule volume (2-7)], for a total of 180 nodules with this appearance. The size of these nodules ranged from 8 to $42 \mathrm{~mm}$. In seven patients with low TSH, ${ }^{131}$ I scintigraphy showed that five nodules were autonomous. Among the remaining 175 spongiform nodules, cytology was benign in 160, insufficient in 10 , and indeterminate in five. There was no case of malignant or suspicious cytology. Eight patients with insufficient cytology and four with indeterminate cytology were submitted to thyroidectomy and histology revealed malignancy in only one of the spongiform nodules. No nodule growth was seen in the three patients with insufficient or indeterminate cytology not submitted to surgery after a minimum follow-up of 24 months. Among spongiform nodules $\geq 2 \mathrm{~cm}(\mathrm{n}=108)$, five were autonomous, 97 were benign, cytology was insufficient in three, and indeterminate in three. Histology revealed the benign nature of the last six nodules.

The present results support the high probability of a benign condition of spongiform nodules, even if the nodule is $\geq 2 \mathrm{~cm}$. These data, together with previous studies (4-7), favor the recommendation that FNA is initially not necessary in cases of nodules with spongiform appearance and is only indicated if the nodule grows during ultrasonographic follow-up, or should be restricted to high-risk patients. The table 1 shows the rates of malignancy reported in the present study and in other series (4-7) on spongiform thyroid nodules.

Table 1. Rate of malignancy in thyroid nodules with spongiform appearance on ultrasonography

\begin{tabular}{lc}
\hline Study (reference) & Rate of malignancy \\
\hline Moon and cols., $2008(4)$ & $1 / 52(2 \%)$ \\
Bonavita and cols., $2009(5)$ & $0 / 210$ \\
Kim and cols., 2010 (6) & $0 / 117$ \\
Virmani and Hammond, 2011 (7) & $0 / 66$ \\
Present series & $1 / 180(0.5 \%)$ \\
All & $2 / 625(0.3 \%)$ \\
\hline
\end{tabular}

1 Programa de Pós-graduação, Santa Casa de Belo Horizonte, Belo Horizonte, MG, Brasil

${ }^{2}$ Serviço de Endocrinologia, Santa Casa de Belo Horizonte, MG, Brasil

Correspondence to: Pedro Weslley Rosario Instituto de Ensino e Pesquisa, Santa Casa de Belo Horizonte Rua Domingos Vieira, 590 30150-240 - Belo Horizonte, MG, Brasil

pedrowsrosario@gmail.com

Received on Oct/18/2014 Accepted on Dec/8/2014

DOI: 10.1590/2359-3997000000112 
Disclosure: no potential conflict of interest relevant to this article was reported.

\section{REFERENCES}

1. Rosário PW, Ward LS, Carvalho GA, Graf H, Maciel RM, Maciel LM, et al. Thyroid nodules and differentiated thyroid cancer: update on the Brazilian consensus. Arq Bras Endocrinol Metabol. 2013;57:240-64.

2. Perros P, Boelaert K, Colley S, Evans C, Evans RM, Gerrard Ba $G$, et al. Guidelines for the management of thyroid cancer. Clin Endocrinol (Oxf). 2014; 81(suppl 1):1-122.

3. Cooper DS, Doherty GM, Haugen BR, Kloos RT, Lee SL, Mandel SJ, et al. Revised American Thyroid Association management guidelines for patients with thyroid nodules and differentiated thyroid cancer. Thyroid. 2009;19:1167-214.

4. Moon WJ, Jung SL, Lee JH, Na DG, Baek JH, LeeYH, et al. Benign and malignant thyroid nodules: US differentiation - multicenter retrospective study. Radiology. 2008;247:762-70.

5. Bonavita JA, Mayo J, Babb J, Bennett G, Oweity T, Macari M, et al. Pattern recognition of benign nodules at ultrasound of the thyroid: which nodules can be left alone? AJR Am J Roentgenol. 2009;193:207-13.

6. Kim DW, Lee EJ, In HS, Kim SJ. Sonographic differentiation of partially cystic thyroid nodules: a prospective study. AJNR Am J Neuroradiol. 2010;31:1961-6.

7. Virmani V, Hammond I. Sonographic patterns of benign thyroid nodules: verification at our institution. AJR Am J Roentgenol. 2011;196:891-5. 